

\section{Investment Portfolios in an Emerging Economy: What Drives Portfolio's Diversification?}

\author{
Pedro Luiz Albertin Bono Milan \\ William Eid Jr.
}

\section{Introduction}

The growth of the financial market in recent years has led to greater availability of financial products and services in order to meet a new range of customers and investors. Among the new products, those intended for financial allocation require special attention because they offer new diversification possibilities and financial strategies for investors. According to Modern Theory of Finance, which has been built since the 1970s, when several investment opportunities are available in the financial market, investors diversify their investments mitigating risks and maximizing rates of return (Markowitz, 1952).

Modern Theory of Finance analyzes the investors' decisions based on assumptions, among them, the market efficiency and individual rationality, where investor decisions are perfectly rational based on the correct analysis of available information (Fama, 1970; Shiller, 1999). However, it is noteworthy that the vast majority of investors do not have diversified portfolios, and many invest without regard to the risk-return relationship. Noting the dissonance between the practice and the Modern Theory of Finance, some studies have begun to question investors' rationality in presenting psychological factors affecting financial decisions and, furthermore, the emotional factors leading investor decisions.

A pioneering study from 1979 states that financial decisions based on emotions or psychological influences can lead investors to allocate their financial resources in higher-risk investments and underdiversified portfolios (Kahneman and Tversky, 1979). The discussion of the rationality of investors in the finance literature leads to the concept of Behavioral Finance, which analyzes investors' decisions under psychology and finance theories highlighting the factors that drive financial decisions.
The Brazilian financial market has a crescent number of investors and several investment possibilities, offering conservative investments ranging from savings and fixed income funds to risky investments via capital markets and structured products. Through the prism of the Modern Theory of Finance, Brazilian investors should allocate their financial resources in a rational and diversified way. On the other hand, according to Behavioral Finance Theory, Brazilian investors can make decisions under psychological bias when choosing underdiversified or risky portfolios.

Few empirical studies analyze Brazilians' investment decisions and the intrinsic characteristics that lead to portfolio diversification and the investment in risky assets. Considering the size and sophistication of the financial market in Brazil, it is important to analyze what drives investment decisions to provide new subsidies to improve the financial education process of Brazilians and provide new tools for market participants to develop better products for investors.

In this context, the main objective of our study is to analyze how Brazilian investors are investing their financial resources among several possibilities available in the market and to seek the factors that can influence the level of portfolio diversification and the financial allocation in risky assets. The paper is organized as follows: The first presents the motivation. The second part debates the underlying literature of financial theories and behavioral influences. The third presents the data and the methodology applied. The fourth discusses the results. The fifth part of the study is devoted to the conclusion.

\section{Underlying Theories}

The Modern Theory of Finance states that investors act rationally, seeking to minimize risks and maximize returns through the process of the diversification of their investments. The theory departs from a neoclassical microeconomic approach whose central paradigm is the rationality of economic agents (Yoshinaga et al., 2008). In this sense, individuals who operate in the financial markets must have the ability to process the information available and to make rational decisions consistent with the concept of Expected Utility (Von Neumann, 1947).

However, over the course of thirty years, many studies have presented evidence of investors allocating financial resources in under-diversified portfolios and unbalanced portfolios concentrated within an average of 
two or three assets (Blume and Friend, 1978) (Barber and Odean 2000) (Polkovnichenko, 2005; Goetzmann and Kumar, 2008). Thus, a new theoretical approach to finance goes considers the individual's behavior in the investment decision. In this context, the Behavioral Finance Theory has the aim of improving the modern theory of finance through psychological and behavioral approaches (Lintner, 1998) (Kimura, Basso and Krauter, 2006). Moreover, cultural differences shape the psychological aspects and play an important role in making economic and financial decisions. Levinson and Peng (2007) suggest that a systematic difference affects financial and economic decisions, whether rational or irrational, often assumed to be universal. The authors conducted an empirical study in the United States and China to examine how cultural background affects economic decision-making and test the framework, information morality and outside groups influence the judgments of financial value and the property across cultures.

Important studies that have incorporated Behavioral Finance Theory present investor decisions driven by psychological needs, following Maslow's Hierarchy of Needs. The Hierarchy of Needs is a concept of motivational behavior, one of the most important motivation theories in psychology studies. In this concept, human actions and decisions are explained by five levels of human needs, ranging from basic physiological needs to the highest level of needs: selfactualization (Maslow, 1943), as presented in Figure 1. At each level of the Hierarchy of Needs, the human being receives internal and external psychological influences that affect their decisions, adding the set of needs that man seeks to meet throughout life.

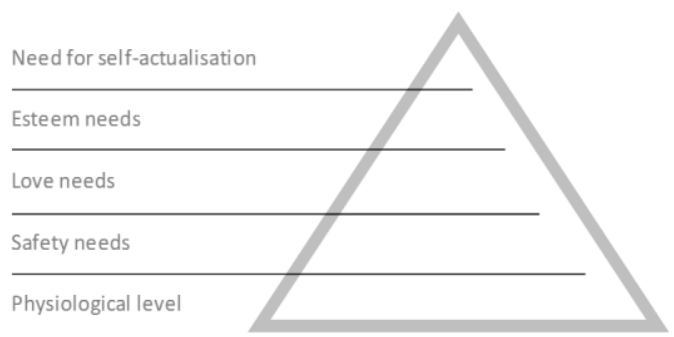

Figure 1. Maslow's Hierarchy of Needs

Source: Hierarchy of Needs, Maslow (1943). Prepared by the authors.

In the context of investments arises the concept of Behavioral Portfolio Theory, which is visually presented in Figure 2, connecting Maslow's Hierarchy of Needs with traditional financial theories (Shefrin and Statman, 2000), (De Brouwer, 2009).

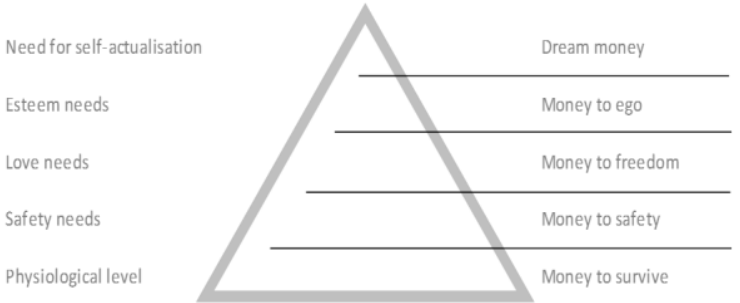

Figure 2. Behavioral Portfolio Theory

Source: Prepared by the authors.

The connection between the theory of behavioral finance and the traditional theory of finance results in three approaches that investors can use in the investment decision-making process (Shefrin e Statman, 2000). The first approach is the Safety-first Portfolio Theory, whereby investors essentially receive the influence of the second level of Maslow's hierarchy. In the safety-first approach, the investor aims to minimize the likelihood of financial distress $\operatorname{Pr}(\mathrm{W}<\mathrm{s})$, where the investor aims to maintain its level of wealth (W) above the subsistence level (s), i.e., above the first level Maslow's Hierarchy of Needs. Investors concentrate their investments in under-diversified portfolios allocated primarily on traditional and low-risk assets.

The second is the PS/A (Theory, Security, Potential and Aspiration Theory). The second theory follows the concepts of Safety-first theory, adding the intrinsic potential of the investor. The potential is the individual aspiration to achieve the highest level of Maslow's Hierarchy of Needs. Security is the major guide of financial decisions, but the investor receives an input from the need to self-actualize. This potential and aspiration lead the investor to create a target point of wealth, a desire for higher levels of wealth. The central difference in this second approach is in the interpretation of the variables. Specifically, the subsistence level (s) replaced by a more general aspiration level (A). Based on this approach, the investor can allocate portions of its investments in risky assets by seeking higher returns. Even though an investor has a potential aspiration for wealth, it keeps a major fraction of its wealth in traditional and low-risk assets.

The third and final approach, BPT-AS (Theory, Security, Potential and Aspiration Theory + Prospect Theory), complements the two previous approaches to Prospect Theory (Kahneman and Tversky, 1979). The Investor's motivation is the security instincts, but invest in different assets by seeking higher rates of return and higher levels of wealth. The difference in this approach is the addition of all cognitive biases in financial decisionmaking. Cognitive biases in investment interfere in mental processes, generating decision biases that may violate the axioms of rationality and leading investors to allocate their resources in investments that generate lower rates of return or assume higher levels of risk. Among the biases are: loss aversion, anchoring, 
availability, herd behavior, local trends and overconfidence (Kahneman and Tversky, 1979), (De Bondt e Thaler, 1994).

Loss aversion may be present only when the investment has improved, imposing a desire to preserve the achieved return. In investments facing losses, investors tend to take greater risks because they believe they can recover past losses by relocating in riskier assets (Köbberling and Walker, 2005). Psychological biases can affect self-control, misleading their comprehension about their actions.

Anchoring is a behavioral bias that biases decisions toward initial values, i.e., a limitation in the decision-making process, leaving the investor tied to a past target return, the result of a payoff from a past time (Jacowitz and Kahneman, 1995). Furthermore, the individual may invest based on available information, called availability bias, whereas investors do not examine other alternatives or additional information to allocate financial resources. Individuals evaluate the chance that some event will happen from the comparable events that have occurred previously (Barberis and Thaler, 2003).

Herd Behavior drives investors to replicate the decisions made by other investors. The belief is that other investors invest with more information; thus, when an individual makes a decision based on what the other investor did, he undervalues the information available in the market (Bikhchandani and Sharma, 2000). Local knowledge can also be present as an investment decision bias if the investor chooses to allocate its resources only in markets in which it already has a level of information and greater familiarity (Coval and Moskowitz, 1999).

The overconfidence bias could lead investors to believe that they have a comparative advantage in the analysis and valuation of assets relative to the market, holding losing positions (Plous, 1993). Few empirical studies seek to understand the behavior of Brazilian investors in light of Behavioral Finance. The discussion in the literature is intriguing and stimulates research to understand whether Brazilian investors allocate their financial resources following the model of rationality or whether they decide by psychological factors.

In the United States, several studies have analyzed the portfolio diversification and investments in risky assets of individual investors. The theories of diversification do not appear to describe investors' decisions properly, given that U.S. investors, analyzed based on the Survey of Consumer Finances 1983, have under-diversified portfolios (Kelly, 1995). As a possible explanation for investor behavior, the overconfidence bias can affect investment decisions and lead investors to less-diversified portfolios and a greater exposure to risky assets. Kelly (1985) tests the effect of various investors' characteristics in the level of portfolio diversification, among them: age, education level, occupation, and risk profiles. However, none of the personal characteristics is significant to improve the understanding of investors' decisions.

A complementary study using data from the Survey of Consumer Finances between 1992 and 2001 seeks to find the determinants of equity investment in the U.S. market (Shum and Faig, 2006). Shum and Faig (2006) include investors' characteristics to understand their financial allocation. Authors note a great heterogeneity in the financial allocation, identifying that the decision to hold equities in investors' portfolios positively correlated with an investor's total investment, age, risk attitude and reasons for saving, such as retirement. Investors aged up to 50 years old tend to have more equities in their portfolios. As investors surpass the age of 50, they reverse this tendency, leading to a reduction in the number of equities. In addition, the total investments and savings have positive effects on equities held in a portfolio.

A study conducted in 2008 analyzes American investor behavior and observes poorly diversified investment portfolios (Goetzmann and Kumar, 2008). The authors note that a low level of diversification is associated with young investors with lower income, less education and less sophistication. From the perspective of Behavioral Finance, Goetzmann and Kumar (2008) state that investment decisions are consistent with overconfidence bias, trend behavior and local bias.

Following, Grable et. al. (2004) attempt to explain why individuals exhibit behaviors that do not maximize the expected utility. The study explores how the projection behavioral bias can shape financial risk tolerance attitudes. The results suggest that changes of gender, income, and stock market prices, analyzed by market indices, help to explain the risk attitudes. Tolerance appears to be risk elastic and attitude changing over time. International studies provide a strong base of empirical support for our testing and allow us to compare the investment portfolios of Brazilians, their level of diversification and investment in risky assets.

\section{Data and Methods}

We use a novel and heterogeneous database composed of 500 Brazilian investors and 2,224 investment observations to attend our empirical investigation. Our database provides sufficient details to deepen the discussion of the investment decisions of Brazilians. We construct our database based on the Brazilian Supreme Electoral Court (TSE-Tribunal Superior Eleitoral) website. The TSE website maintains 
the investment portfolios of candidates for the political positions of mayors and councilors in the year 2012 for all Brazilian states.

Investors are Brazilians with heterogeneous occupations not based on political occupation. By opting for the candidacy for a political position in Brazil, the candidate must release all of its assets and investments in the Supreme Electoral Tribunal website. While we understand that there may be a selection bias in the study sample, to our knowledge, it is the only database publicly available. Moreover, we believe that the impact is minimum by the sample size, the heterogeneity in the occupations of these people and the differences in their investment portfolios, serving as a good proxy for the investment portfolios of Brazilians.

Our database reports detailed allocations in different assets with at least 17,000 Reais and at most of 11 million Reais of investments, and we account for personal characteristics such as age, gender, marital status, education level, residence in the capital city or countryside and total investment. The total investment of each investor is in natural logarithm to capture the variation between investment portfolios without distorting the results.

The average age of investors, presented in Table 1, is 53 years old, with a minimum of 30 years and a maximum of 87 years old. These investors allocate their resources in four different types of assets on average, with a minimum investment of 1 and a maximum of 13 different assets. Observing the number of investments, we can determine that the average Brazilian investor is under-diversified. Among all investors, 435 are men and 75 are women, 344 are married, 391 have higher education, and $56 \%$ of them reside in capital cities.

Table 1: Summary Statistics of investors' characteristics

\begin{tabular}{cccc}
\hline & $\begin{array}{c}\text { Age } \\
\text { (years) }\end{array}$ & $\begin{array}{c}\text { Total Investment } \\
(\mathrm{R} \$)\end{array}$ & $\begin{array}{c}\text { Number of } \\
\text { investments }\end{array}$ \\
\hline Mean & 53 & $731,669.55$ & 4.45 \\
Median & 54 & $462,067.64$ & 4 \\
Std. Dev. & 11 & $988,523.13$ & 1.76 \\
Min & 30 & $17,577.52$ & 1 \\
Max & 87 & $11,186,074.14$ & 13 \\
N & 500 & 500 & 500 \\
\hline Man & $\mathrm{N}$ & $\%$ & \\
Woman & 725 & $85 \%$ & \\
Married & 345 & $15 \%$ & \\
Not Married & 156 & $69 \%$ & \\
Higher Education & 391 & $31 \%$ & \\
No Higher Educ. & 109 & $22 \%$ & \\
Residence in & 282 & $56 \%$ & \\
Capital & & & \\
Residence in & 218 & $44 \%$ & \\
Countryside & & & \\
\hline
\end{tabular}

Source: TSE - Tribunal Superior Eleitoral 2012.

Prepared by the authors.

Table 2 shows the allocation of Brazilian investors in different assets. Investors allocate most of their investments in residential real estate, followed by vehicles and urban land. Table 2 shows the underdiversified portfolios and a conservative allocation with approximately $70 \%$ allocated to traditional and low-risk assets. It is important to highlight the resources allocated in vehicles, durables that traditionally do not generate positive financial returns. Financial investments represent approximately $15 \%$ of the total polarized in fixed income assets, reinforcing the evidence of conservative investor profiles.

Table 2: Asset Allocation (\% Participation)

\begin{tabular}{llll}
\hline Residentialreal estate & $44.70 \%$ & Capitalization & $0.36 \%$ \\
Vehicles & $13.46 \%$ & Loanstothird parties & $0.31 \%$ \\
Urbanland & $8.66 \%$ & Miscellaneous equipment & $0.27 \%$ \\
Entrepreneurial & $5.42 \%$ & Livestock & $0.26 \%$ \\
Commercialproperty & $4.68 \%$ & Equity Mutual Funds & $0.22 \%$ \\
Current account & $4.62 \%$ & Other goods & $0.19 \%$ \\
Ruralreal estate & $4.48 \%$ & Telephoneline & $0.10 \%$ \\
Fixed income secunties & $4.40 \%$ & Investments abroad & $0.04 \%$ \\
Savings & $3.32 \%$ & Club Membership & $0.03 \%$ \\
Other funds & $1.18 \%$ & Repo operations & $0.02 \%$ \\
Phivate social secunty & $0.99 \%$ & Boats & $0.02 \%$ \\
Stocks & $0.73 \%$ & Jewelry, painting, art, & \\
Fixed income funds & $0.53 \%$ & collectors, antique, etc. & $0.02 \%$ \\
Consortium & $0.49 \%$ & Hedge funds & $0.01 \%$ \\
Improvements & $0.46 \%$ & Gold & $0.01 \%$ \\
\hline
\end{tabular}

Source: TSE - Tribunal Superior Eleitoral 2012. Prepared by the authors.

Figure 3 graphically presents the main investments made by investors.

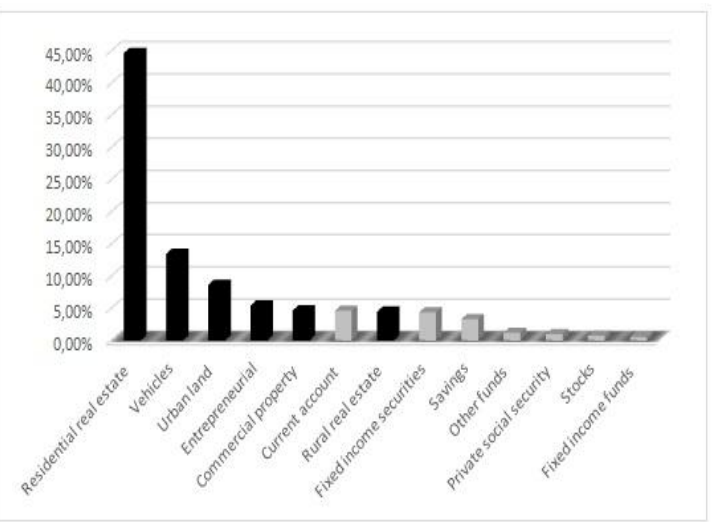

Figure 3. Asset Allocation (\% Participation)

Source: TSE - Tribunal Superior Eleitoral 2012. Prepared by the authors.

The black vertical bars represent non-financial investments; the gray vertical bars represent financial investments. Stratifying the sample by total investments, we observe that there is a thin shift in asset allocation. As total investments increase, allocations in residential real estate and vehicles decline, and allocations in rural properties and entrepreneurial and financial allocations increase. However, investor portfolios remain underdiversified. 
Table 3: Allocation of the main investments by total investment (in $\mathbf{R} \$$ )

\begin{tabular}{lccccc}
\hline Investment & $<500 \mathrm{k}$ & $\Delta \%$ & $\begin{array}{c}>500 \mathrm{k} \text { and } \\
\mathrm{mm}\end{array}$ & $\Delta \%$ & $>1 \mathrm{~mm}$ \\
\hline Residentialreal estate & $44.14 \%$ & $8.42 \%$ & $47.86 \%$ & $-11.76 \%$ & $42.23 \%$ \\
Vehicles & $17.50 \%$ & $-37.48 \%$ & $10.94 \%$ & $-46.16 \%$ & $5.89 \%$ \\
Urbanland & $9.75 \%$ & $-30.20 \%$ & $6.81 \%$ & $18.93 \%$ & $8.09 \%$ \\
Entreprenemial & $4.43 \%$ & $7.67 \%$ & $4.77 \%$ & $85.21 \%$ & $8.84 \%$ \\
Commercialproperty & $2.94 \%$ & $91.43 \%$ & $5.62 \%$ & $44.27 \%$ & $8.11 \%$ \\
Current account & $4.55 \%$ & $-12.47 \%$ & $3.98 \%$ & $40.64 \%$ & $5.60 \%$ \\
Ruralreal estate & $3.89 \%$ & $14.62 \%$ & $4.45 \%$ & $36.73 \%$ & $6.09 \%$ \\
Fixed income secunities & $4.42 \%$ & $15.59 \%$ & $5.10 \%$ & $-32.25 \%$ & $3.46 \%$ \\
Savings & $3.72 \%$ & $-21.47 \%$ & $2.92 \%$ & $-5.11 \%$ & $2.77 \%$ \\
Other funds & $0.82 \%$ & $85.37 \%$ & $1.53 \%$ & $11.35 \%$ & $1.70 \%$ \\
Pivate social secunity & $0.67 \%$ & $126.68 \%$ & $1.52 \%$ & $-22.76 \%$ & $1.17 \%$ \\
Stocks & $0.40 \%$ & $128.71 \%$ & $0.91 \%$ & $49.43 \%$ & $1.36 \%$ \\
Fixed income funds & $0.57 \%$ & $-14.64 \%$ & $0.49 \%$ & $-0.45 \%$ & $0.49 \%$ \\
\hline
\end{tabular}

Source: TSE - Tribunal Superior Eleitoral 2012. Prepared by the authors.

Figure 4 graphically presents the changes in asset allocations as total investments increase.

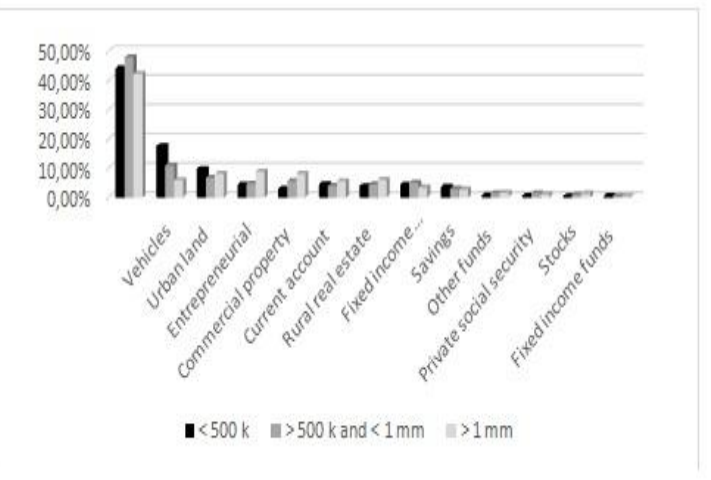

Figure 4. Changes in asset allocations as total investments increase

Source: TSE - Tribunal Superior Eleitoral 2012. Prepared by the authors.

\subsection{Diversification Metrics}

To estimate the level of portfolio diversification, we follow the diversification metric presented by Blume and Friend, 1978. The metric analyzes investor allocations compared to a market portfolio. Blume and Friend, 1978 analyze the stock portfolios of U.S. investors using the capital market index as a benchmark to measure the diversification index. Whereas Brazilian investors allocate little financial resources in stocks and the absence of a market benchmark for these investors, we adjust the metric creating a market portfolio based on the mean and median allocations of all investors in our database.

Our adaptation analyzes the deviation of the individual allocation of each asset compared to the mean and median allocations of each asset among all investors in the sample. Thus, assuming that the mean and median portfolios are a good representation of the portfolio allocation of Brazilians, the mean and median of all investments in each asset are the benchmark in our study. We understand that our adaptation can indicate a specification error because there is not a benchmark publicly available; however, examining how individual investors differ from the mean and median allocation of all investors can be a good starting point to understand the factors leading Brazilian investors to diversify their portfolios. According to the metric, the lower the index measured by Equations 1 and 2, the greater the portfolio diversification.

Thus, the level of portfolio diversification follows Equation (1) and Equation (2):

$$
\text { DImean }_{i}=\sum_{i=1}^{N}(w i-w \text { Benchmeani })^{2}
$$

$$
\begin{aligned}
& \text { DImedian }_{i} \\
& =\sum_{i=1}^{N}(w i-w \text { Benchmediani })^{2}
\end{aligned}
$$

Where:

DImean $_{i}$ is the diversification index using the mean of investor $\mathrm{i}$

DImedian $_{\mathrm{i}}$ is the diversification index using the median of investor $\mathrm{i}$

$\mathrm{N}$ is the number of securities held by the investor

$\mathrm{w}_{\mathrm{i}}$ is the portfolio weight assigned to investment type $\mathrm{i}$ in the investor portfolio

wbenchmean $_{\mathrm{i}}$ is the mean weight assigned to an investment type $\mathrm{i}$ in the benchmark portfolio wbenchmedian $_{I}$ is the median weight assigned to an investment type $\mathrm{i}$ in the benchmark portfolio

\subsection{Metrics of Investment in Risky Assets}

Whereas Brazilian investors have concentrated portfolios in low-risk assets, we seek to understand what drives investors to take a divergent allocation. We use higher-risk investments and p personal characteristics to pursue factors that can lead investors to allocate financial resources in different assets. Stocks, equity mutual funds and entrepreneurial investments are risky investments in our study.

We measure the level of allocation in risky assets via two procedures:

The first procedure considers the weighted sum of risky assets contained in each individual portfolio. The 
formula allows us to observe the relative percentage of total investments allocated in risky assets.

Equation (3) presents the formula for measuring the level of risk allocation:

$$
\begin{aligned}
& \operatorname{Irisk}_{i} \\
& =\sum^{N}\left(\frac{\text { Wrisk }_{i}}{\text { Total }_{i}}\right)
\end{aligned}
$$

Where,

Irisk $_{\mathrm{i}}$ is the risk-taking index of investor $\mathrm{i}$

Wrisk $_{\mathrm{i}}$ is the sum of all risk investments of investor $\mathrm{i}$

Total $_{\mathrm{i}}$ is the sum of all investments of investor $\mathrm{i}$

The second procedure to measure the allocation in risky assets follows Shum and Faig (2006), adding a dichotomous variable that takes the value of 1 if investors invest in risky assets or 0 if the investor has no risky assets in its investment portfolio.

\begin{tabular}{c|cc}
$\begin{array}{c}\text { Risk } \\
\text { Investment } \\
\text { Index }\end{array}$ & if risky assets $\neq 0$ & variable value $=1$ \\
if risky assets $=0$ & variable value $=0$
\end{tabular}

Finally, to find the factors that influence investors to adopt a more diversified portfolio, we developed an OLS regression model using the diversification index measured by Equation (1) and Equation (2) as explained variables. As explanatory variables, we use the investors' characteristics: age $(\Omega)$, gender $(\lambda)$, level of education $(\delta)$, residence $(\theta)$ (capital city or countryside), marital status $(\xi)$ and total investment $(\Psi)$. The objective of this regression model is to capture the intrinsic characteristics that lead to diversified allocations. The regressions relied on the application of a robust White Matrix.

Equation (1) as an explained variable follow the OLS Equation 4:

DImean $_{i}=\beta_{0}+\beta_{1} \Omega_{i}+\beta_{2} \lambda_{i}+\beta_{3} \delta_{i}+\beta_{4} \theta_{i}+\beta_{5} \xi_{i}+$ $\beta_{6} \Psi_{i}+\varepsilon$

Equation (2) as an explained variable follow the OLS Equation 5:

DImedian $_{i}=\beta_{0}+\beta_{1} \Omega_{i}+\beta_{2} \lambda_{i}+\beta_{3} \delta_{i}+\beta_{4} \theta_{i}+$ $\beta_{5} \xi_{i}+\beta_{6} \Psi_{i}+\varepsilon$

Similar to equations 4 and 5, to find the factors that influence investors to allocate resources in risky assets, we developed two regression models to verify the impact of age $(\Omega)$, gender $(\lambda)$, level of education $(\delta)$, residence $(\theta)$ (capital city or countryside), marital status $(\xi)$ and total investment $(\Psi)$ on the decision to allocate financial resources in risky assets. The first regression is an OLS regression and has the explanatory variable measured by the first risk metric procedure, Equation 3. The second regression, conducted under the second risk metric procedure, has dichotomous explained variables; therefore, we adopted a Probit model. The regressions relied on the application of a robust White Matrix.

Equation (3) as an explained variable follow the OLS Equation (6):

Irisk $_{i}=\beta_{0}+\beta_{1} \Omega_{i}+\beta_{2} \lambda_{i}+\beta_{3} \delta_{i}+\beta_{4} \theta_{i}+\beta_{5} \xi_{i}+$ $\beta_{6} \Psi_{i}+\varepsilon$

Procedure (2) as a dichotomous explained variable follow the Probit Equation (7):

Probitrisk $_{\cdot i}=\beta_{0}+\beta_{1} \Omega_{i}+\beta_{2} \lambda_{i}+\beta_{3} \delta_{i}+\beta_{4} \theta_{i}+$ $\beta_{5} \xi_{i}+\beta_{6} \Psi_{i}+\varepsilon$

\section{Results}

Our results provide new insights about how Brazilian investors allocate their financial resources. The results indicate that investors have under-diversified portfolios concentrated mainly in traditional and low-risk assets. The average rate of diversification estimated by Equation 1 is 0.2153 . The diversification index using the benchmark portfolio composed by the median allocations, Equation (2) presents an average diversification rate of approximately 0.5023 . Despite the difference between the two models, we observe that the difference extends to all individual portfolios in proportional magnitude, preserving the comparative power between the models. Table 4 shows diversification rates in quartiles, and quartile 1 (Q1) indicates investors with higher levels of diversification. The diversification index becomes smaller as we move from the second quartile to the fourth quartile.

There is a significant difference between investors with high diversification index, first quartile, and investors located in the fourth quartile for both metrics diversification. However, the differences must to be statistically significant to give consistency to the inferences. To test for significant differences between the investors with greater diversification rates and investors with smaller diversification rates, we conducted a t-test of means between the Q1 and Q4 groups. 
Table 4: Descriptive statistics of diversification rates

\begin{tabular}{lrrrrr}
\hline & DImean & Q1 & Q2 & Q3 & Q4 \\
\hline Mean & 0.2153 & 0.0560 & 0.1103 & 0.2037 & 0.4911 \\
Median & 0.1536 & 0.0582 & 0.1070 & 0.2019 & 0.4385 \\
Std. Dev. & 0.1926 & 0.0157 & 0.0204 & 0.0315 & 0.1849 \\
Min & 0.0192 & 0.0807 & 0.0807 & 0.1537 & 0.2719 \\
Max & 0.9124 & 0.1534 & 0.1534 & 0.2709 & 0.9124 \\
$\mathrm{~N}$ & 500 & 125 & 125 & 125 & 125 \\
\hline \hline & DImedian & $\mathrm{Q} 1$ & $\mathrm{Q} 2$ & $\mathrm{Q} 3$ & $\mathrm{Q} 4$ \\
\hline Mean & 0.5023 & 0.2934 & 0.4193 & 0.5270 & 0.7697 \\
Median & 0.4673 & 0.2992 & 0.4172 & 0.5227 & 0.7796 \\
Std. Dev. & 0.1865 & 0.0531 & 0.0286 & 0.0370 & 0.1062 \\
Min & 0.1584 & 0.1584 & 0.3695 & 0.4673 & 0.6113 \\
Max & 10.000 & 0.3694 & 0.4672 & 0.6094 & 10.000 \\
$\mathrm{~N}$ & 500 & 125 & 125 & 125 & 125 \\
\hline
\end{tabular}

Source: Prepared by the authors

The t-test compares the rates of portfolio diversification in the first quartile, which has higher diversification rates, with the lower diversification rates located in the fourth quartile. The test revealed a statistically significant difference at $1 \%$ with t-stat $<0.000$ for both models, ensuring that investors distributed in the first quartile had significantly different portfolios than investors located in the fourth quartile. This t-test validates the inferences for each group in the regression models.

The regression models intend to identify aspects that can lead investors to increase their diversification levels and characteristics that can drive investors to increase investments in risky assets in their portfolios. Table 5 presents the results of the four regression models. Columns (1) and (2) identify the characteristics of investors that can lead to a more diversified portfolio. Columns (3) and (4) present the characteristics that lead investors to invest greater financial resources in risky assets.
Table 5: Results of the four regression models

\begin{tabular}{|c|c|c|c|c|}
\hline \multirow[t]{3}{*}{ Equation } & (4) & (2) & (6) & $\stackrel{(7)}{\mathrm{PROBT}}$ \\
\hline & & & & \\
\hline & \multicolumn{2}{|c|}{ Diversification } & \multicolumn{2}{|c|}{ Risky assets } \\
\hline Vaziables & DIman & Dimedinn & & \\
\hline \multirow[t]{2}{*}{ Agg ( $(\Omega)$} & 0.001 & 0.000 & $-0.002^{* * *}$ & $-0.013^{* *}$ \\
\hline & (1.31) & $(0.12)$ & $(.329)$ & (-239) \\
\hline \multirow[t]{2}{*}{ D. $\operatorname{Man}(\lambda)$} & 0.002 & -0.011 & $0.036 * *$ & $0.46^{7 * * *}$ \\
\hline & $(0.07)$ & $(-0.47)$ & (247) & (2.68) \\
\hline \multirow[t]{2}{*}{ D. HighEdvection (8) } & $-0.049 * *$ & .0 .004 & -0.031 & 0.172 \\
\hline & $(-2.16)$ & $(-022)$ & $(-1.58)$ & (1.19) \\
\hline \multirow[t]{2}{*}{ D. Capitalicity ( $(\theta)$} & 0.012 & 0.020 & 0.005 & 0.108 \\
\hline & $(-0.71)$ & (1.17) & (0.34) & (090) \\
\hline \multirow[t]{2}{*}{ D. Marnied (乡) } & $-0.083 * * *$ & $-0.037 * *$ & $-0.032^{*}$ & .0205 \\
\hline & (-4.11) & $(-197)$ & $(-1.87)$ & $(-1.61)$ \\
\hline \multirow[t]{2}{*}{ Total Investment (צ) } & $0.020^{*}$ & .0 .011 & $0.032^{* * *}$ & $0.244^{* * * *}$ \\
\hline & (1.74) & $(-1.05)$ & (3.23) & (359) \\
\hline $\mathrm{N}$ & 500 & 500 & 500 & 500 \\
\hline Adjusted Rsquared & 0.0665 & 0.0048 & 0.0776 & - \\
\hline Psevdo R-squared & . & . & . & 0.0504 \\
\hline
\end{tabular}

Source: Prepared by the authors

Notes for Table 6: Regression Table for models of diversification and investment in risky assets. (1)(2) OLS regression model with a diversification index measured by Equation 1 and Equation 2 as an explained variable and the variables Age $(\Omega)$, gender $(\lambda)$, education level $(\delta)$, residence $(\theta)$ (capital city or countryside), marital status $(\xi)$ and total investment $(\Psi)$ as explanatory variables. (3)(4) Regression models to verify the impact of Age $(\Omega)$, gender $(\lambda)$, education level $(\delta)$, residence $(\theta)$ (capital city or countryside), marital status $(\xi)$ and total investment ( $\Psi$ ) in risky assets. Regression (3) is an OLS regression has explained the variable measured by Equation 3. Regression (4) is a Probit model that analyzes the impact of the explanatory variables on the level of investment in risky assets. The regressions relied on the application of a robust White Matrix

The results displayed in Table 5 indicate the effects of investor characteristics on the level of portfolio diversification as well as the propensity to invest in risky assets. The characteristics of Brazilian investors play an important role in investment decisions, and the results support the findings in international studies. Higher education influences investors to higher levels of portfolio diversification. The result has statistical significance and follows evidence found by Goetzmann and Kumar (2008) for American investors. Marital status also positively affects the level of portfolio diversification. Married investors tend to have more diversified portfolios than single investors do.

Goetzmann and Kumar (2008) observe more diversified portfolios in the United States as total investment increases, contrary to our finding for Brazil. In Brazil, higher financial resources do not necessarily lead to more diversified portfolios. In the presence of new financial resources, the Brazilian investors maintain 
their resources in the same types of investments. If the investor allocates its resources in residential real estate, land and savings, he will not necessarily allocate its resources in other assets, and in the presence of new financial resources, an investor will allocate more resources in the same types of assets.

Comparing the results concerning investment in risky assets, we observe that a greater number of personal characteristics affect the investment decisions of Brazilian investors. The equations in models 6 and 7 seek the characteristics of investors that lead them to invest in risky assets. For both models, shown in columns (3) and (4) of Table 6, age may indicate higher risk exposure. The evidence accompanying the results found in the study of Shum and Faig (2006) in the United States shows that younger investors tend to invest more in risky assets.

The model also shows that male investors have a $43 \%$ greater likelihood of investing in risky assets than female investors, highlighting the discussion on gender and investment decisions. Married investors tend to exhibit less risk and maintain conservative portfolios. As expected, as total investments increase, the greater the investment in risky assets will be, once more in line with the results of Shum and Faig (2006).

Following international studies, our results suggest that Brazilian investors in our dataset cannot follow the complete model of rationality assumed by the Modern Finance Theory. Evidence suggests that their investment decisions are subject the psychological interference defined in Behavioral Finance theory, leading to poorly diversified portfolios. In addition, behavioral biases can lead the investor to allocate resources in risky assets regardless of the risk factors.

Analyzing the study by Shefrin and Statman (2000), our results suggest that Brazilian investors make financial decisions that are consistent with the BPT-AS Theory approach (Theory, Security, Potential and Aspiration Theory + Prospect Theory). Investors can move essentially by security instinct, but a potential aspiration to higher levels of wealth can lead the investor to invest a portion of its assets in risky assets, seeking higher rates of return.

The results that present Brazilian investors as less diversified with a high concentration of traditional and low-risk assets in their portfolios and a fraction of their resources in risky assets support the possibility that these investors may be subject to psychological biases in financial decisions. Personal characteristics that lead investors to take greater risk suggest individual overconfidence, a behavioral bias that leads investors to believe that their ability to process information is better than that of other investors, leading to greater exposure to risk. Age can play a strong role to overconfidence, given that younger investors tend to take greater risks. Goetzmann and Kumar (2008) and Kelly (1985) indicate overconfidence bias as an important factor that affects financial decisions.

Married and high-educated investors are more conservative and invest less in risky assets. The results reinforce the theory of safety first. In addition, underdiversified portfolios that are concentrated in traditional assets may follow the herd effect, a psychological bias that leads investor to invest only in well-known assets and local assets.

Although our results are in line with the results of international studies that examine investors in the United States, there is a significant difference between Brazilian and American investors in terms of the allocation of resources. Most American investments are concentrated in financial assets, while most Brazilians investments are concentrated in non-financial assets. The Federal Reserve Bulletin 2012 reveals that American investors mainly focused on financial investments.

Table 6 and Figure 5 present investor allocation in the United States.

Table 6: Asset Allocation held by investors in the United States (\% of Portfolio)

\begin{tabular}{lclc}
\hline Investment & $\%$ & Investment & $\%$ \\
\hline Residentialreal estate & $23.70 \%$ & Real estate equity & $3.35 \%$ \\
Retirement accounts & $19.05 \%$ & Vehicles & $2.60 \%$ \\
Business equity & $14.10 \%$ & Bonds & $2.20 \%$ \\
Mutual funds & $7.50 \%$ & Certificates of deposit & $1.95 \%$ \\
Stocks & $7.00 \%$ & Life insurance & $1.25 \%$ \\
Transaction accounts & $6.65 \%$ & Other nonfinancial & $0.65 \%$ \\
Other property & $5.60 \%$ & Savings bonds & $0.15 \%$ \\
Other financialinvestments & $4.25 \%$ & & \\
\hline
\end{tabular}

Source: Federal Reserve Bulletin 2012. Prepared by the authors.

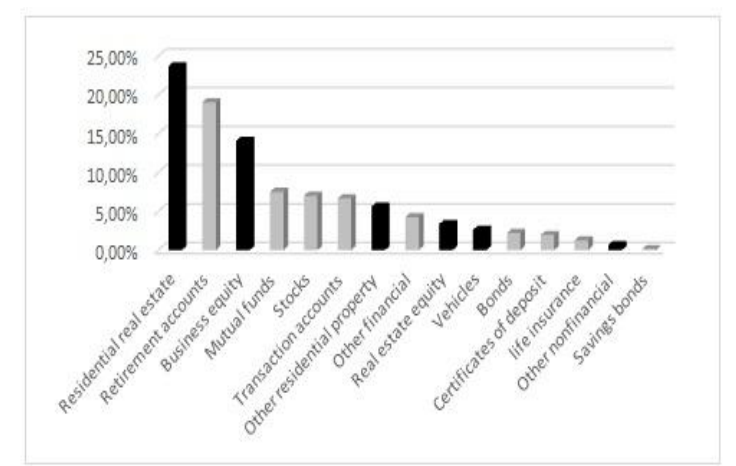

Figure 5. Percentage Allocation of the major investments held by US investors

Source: Federal Reserve Bulletin 2012. Prepared by the authors. 
The black vertical bars represent non-financial investments and the gray vertical bars represent financial investments.

\section{Conclusion}

This empirical study examines the level of portfolio diversification of Brazilian investors, focused on aspects that can influence portfolio diversification and the intrinsic characteristics that can lead investors to allocate financial resources in risky assets, furthering the discussion on the investment decisions within an emerging economic context. Moreover, the study sheds light on the possible cognitive influences built by behavioral economic theory.

From a new and heterogeneous database composed of 500 Brazilian investors and 2,224 observations of investments, it became clear that Brazilian investors allocate their resources in underdiversified portfolios concentrated in only four different types of investments on average. In addition, investors allocate approximately $92 \%$ of their resources in low-risk assets. Brazilians investments concentrate investments in fixed-income assets, reinforcing the conservative investor profile.

The results suggest that the characteristics of investors studied can play an important role in Brazilian investment decisions. The results indicate that investors endowed with higher education tend to have a higher rate of portfolio diversification. In addition, married investors tend to have more diversified portfolios, distributing their resources in different assets.

The investment decisions of Brazilians lead to low portfolio diversification allocated primarily in lowrisk assets, and they suggest the limitations of investor rationality theory advocated by the Modern Theory of Finance. Economic, sociological and psychological concepts may play an important role in explaining the economic decisions in real life. Thus, investment decisions may be subject to behavioral influence as defined in the Behavioral Finance literature.

Among the characteristics that lead investors to allocate resources in risky assets are age, gender, marital status and education level.

Although this study achieves the proposed objectives, there are caveats that need to be identified, such as the possible bias generated by the investment database and the benchmarks adopted. These issues do not invalidate the evidence obtained during this study, but they serve as a warning to the possibility of new evidence by the improvement in the dataset. Future studies should apply or develop models that best explain the relationship between investment decisions and the effects of psychological biases defined by Behavioral Finance Theory. New studies can contribute significantly to understand the purpose of this study, and we recommend a replication of the study with the inclusion of a larger number of investor portfolios.

\section{REFERENCES}

Arzac, E. R., \& Bawa, V. S. (1977). Portfolio choice and equilibrium in capital markets with safety-first investors. Journal of Financial Economics, 4(3), 277-288.

Barber, B. M., \& Odean, T.. Trading is hazardous to your wealth: The common stock investment performance of individual investors. The Journal of Finance, 55(2), 773-806.

Barberis, N., \& Thaler, R. (2003). A survey of behavioral finance. Handbook of the Economics of Finance, 1, 1053-1128.

Bikhchandani, S., \& Sharma, S. (2000). Herd behavior in financial markets. IMF Staff papers, 279-310.

Blume, M., \& Friend, I. (1978). The changing role of the individual investor: Wiley New York.

Coval, J. D., \& Moskowitz, T. J. (1999). Home bias at home: Local equity preference in domestic portfolios. The Journal of Finance, 54(6), 2045-2073.

De Bondt, W. F., \& Thaler, R. H. (1994). Financial decision-making in markets and firms: A behavioral perspective: National Bureau of Economic Research.

De Brouwer, P. J. (2009). Maslowian portfolio theory: an alternative formulation of the behavioural portfolio theory. Journal of Asset Management, 9(6), 359-365.

Fama, E. F. (1970). Efficient capital markets: A review of theory and empirical work*. The journal of Finance, 25(2), 383-417.

Goetzmann, W. N., \& Kumar, A. (2008). Equity portfolio diversification*. Review of Finance, 12(3), 433-463. 
Grable, J., Lytton, R., \& O'Neill, B. (2004). Projection bias and financial risk tolerance. The Journal of Behavioral Finance, 5(3), 142-147

Jacowitz, K. E., \& Kahneman, D. (1995). Measures of anchoring in estimation tasks. Personality and Social Psychology Bulletin, 21, 1161-1166.

Kahneman, D., \& Tversky, A. (1979). Prospect theory: An analysis of decision under risk. Econometrica: Journal of the Econometric Society, 263-291.

Kelly, M. (1995). All their eggs in one basket: Portfolio diversification of US households. Journal of Economic Behavior \& Organization, 27(1), 87-96.

Kimura, H., Basso, L. F. C., \& Krauter, E. (2006). Paradoxos em finanças: teoria moderna versus finanças comportamentais. Revista de Administração de Empresas, 46(1), 4158.

Köbberling, V., \& Wakker, P. P. (2005). An index of loss aversion. Journal of Economic Theory, 122(1), 119-131.

Levinson, J. D., \& Peng, K. (2007). Valuing cultural differences in behavioral economics. ICFAI journal of behavioral finance, 4, 32-47.

Lintner, G. (1998). Behavioral finance: Why investors make bad decisions. The Planner, 13(1)7-8.

Markowitz, H. (1952). Portfolio selection*. The journal of finance, 7(1), 77-91.

Maslow, A. H. (1943). A theory of human motivation. Psychological review, 50(4), 370 .

Plous, S. (1993). The psychology of judgment and decision making: Mcgraw-Hill Book Company.

Polkovnichenko, V. (2005). Household portfolio diversification: A case for rank-dependent preferences. Review of Financial Studies, 18(4), 1467-1502.
Shefrin, H., \& Statman, M. (2000). Behavioral portfolio theory. Journal of financial and quantitative analysis, 35(02), 127151.

Shiller, R. J. (1999). Human behavior and the efficiency of the financial system. Handbook of macroeconomics, 1, 1305-1340.

Shum, P., \& Faig, M. (2006). What explains household stock holdings? Journal of Banking \& Finance, 30(9), 2579-2597.

Von Neumann, J. (1947). Morgenstern, 0.(1944) Theory of Games and Economic Behavior. Princeton: Princeton UP.

Yoshinaga, C. E., de Oliveira, R. F., da Silveira, A. D. M., \& Barros, L. A. B. d. C. (2008). Finanças Comportamentais: uma introdução. REGE Revista de Gestão, 15(3), 25-35. 